\title{
Air pollution and low birth weight: a historical cohort study from Tehran
}

M. Araban, ${ }^{1}$ N. Kariman,,${ }^{2}$ S.S. Tavafian, ${ }^{3}$ S. Motesaddi, ${ }^{4}$ H. Alavimajd ${ }^{5}$ and F. Amin Shokravi ${ }^{3}$

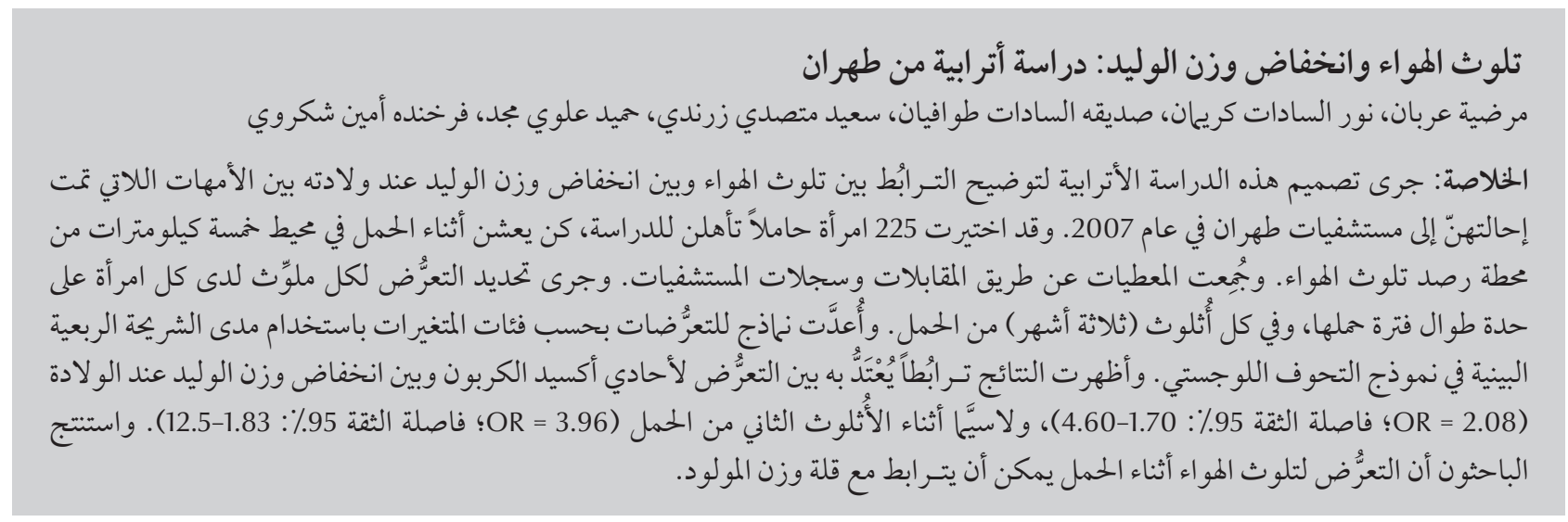

ABSTRACT This historical cohort study was designed to clarify the association between air pollution and low birth weight (LBW) amongst women referred to Tehran hospitals in 2007. In total, 225 eligible pregnant women who lived within $5 \mathrm{~km}$ of an air pollution monitoring station during their pregnancy were selected for the study. Data were collected via interview and hospital records. Exposure to each pollutant was estimated for each woman individually throughout her pregnancy and for each trimester. Exposures were modelled as categorical variables using inter-quartile ranges in a logistic regression model. The results showed a significant association between exposure to $\mathrm{CO}$ and $\mathrm{LBW}(\mathrm{OR}=2.08,95 \% \mathrm{Cl}: 1.70-4.60)$, particularly during the second trimester $(\mathrm{OR}=3.96, \mathrm{Cl}$ : 1.83-12.5. We conclude that exposure to air pollution during pregnancy may be associated with LBW.

\section{Pollution atmosphérique et faible poids de naissance : une étude de cohorte historique à Téhéran}

RÉSUMÉ La présente étude de cohorte historique a été conçue pour clarifier l'association entre la pollution atmosphérique et le faible poids de naissance des enfants nés de mères orientées vers des hôpitaux de la ville de Téhéran en 2007. Au total, 225 femmes enceintes éligibles et vivant dans un rayon de cinq kilomètres d'une station de surveillance de la pollution atmosphérique pendant leur grossesse ont été sélectionnées pour participer à l'étude. Les données ont été recueillies au moyen d'un entretien et des dossiers hospitaliers. L'exposition à chaque polluant a été estimée pour chaque femme individuellement, tout au long de la grossesse et pour chaque trimestre. Les expositions ont été modélisées en tant que variables nominales avec des plages interquartiles dans un modèle de régression logistique. Les résultats ont révélé qu'il existait une association significative entre l'exposition au monoxyde de carbone et un faible poids de naissance (O.R. = 2,08; IC à $95 \%$ : $1,70-4,60)$, notamment pendant le deuxième trimestre (O.R. =3,96; IC :1,83-12,5). Nous en avons conclu qu'une exposition à la pollution atmosphérique au cours de la grossesse peut être associée à un faible poids de naissance.

${ }^{7}$ PhD student, Faculty of Nursing and Midwifery; ${ }^{4}$ Department of Environmental Health Engineering; ${ }^{5}$ Department of Biostatistics, Shaheed

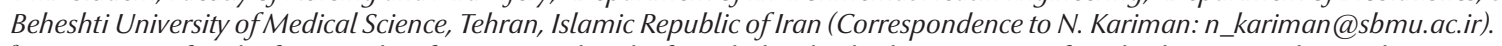
${ }^{2}$ Department of Midwifery, Faculty of Nursing and Midwifery, Shaheed Beheshti University of Medical Science, Tehran, Islamic Republic of Iran ${ }^{3}$ Department of Health Education, University of Tarbiat Modares, Tehran, Islamic Republic of Iran.

Received: 30/09/10; accepted: 08/11/10 


\section{Introduction}

Low birth weight (LBW) is known as one of the most important factors associated with prenatal and neonatal mortality, and has been established as a determinant of neonatal mortality [1]. It is also significantly associated with infant and childhood morbidities, ranging from pulmonary infection to myocardial infarction, stroke, hypertension and diabetes [2-4]. Given the importance of LBW consequences, assessing its' risk factors is guaranteed.

As previously reported, low socioeconomic status, drug addiction, maternal malnutrition and anaemia, maternal age, weight gain during pregnancy as well as birth order are significantly associated with LBW $[5,6]$.

Although several studies have examined the relationship between maternal exposure to air pollution and LBW [7-15], a definitive association between exposure during pregnancy and LBW is still not established [14]; some researchers identified a relationship [15] but others did not [13]. The trimester-specific findings from these studies are inconsistent, and the most vulnerable trimester of pregnancy has not been identified. Furthermore, the most critical problem in these studies is that they did not control the other risk factors of LBW beyond air pollution exposure.

Tehran, the capital city of the Islamic Republic of Iran, is one of the most polluted cities in the world [16]. Given the importance of LBW consequences and the probably effect of exposure to pollutants on birth weight, we aimed to examine the association between ambient air pollution and LBW among babies born to women referred to Tehran hospitals.

\section{Methods}

A historical cohort study was conducted in the maternity wards of 6 teaching hospitals affiliated to medical science universities in Tehran. The ethics committee of Shaheed Beheshti University of Medical Sciences approved the study.

Data on all singleton term births ( $\geq 37$ gestational weeks) of eligible pregnant women who gave birth between 1 June and 30 September 2007 were obtained through interviewing the women and from hospital puerperal records of mothers and their babies. We chose this study period because it covered the most polluted season in the year. Women were eligible for the study if they were living within 5 $\mathrm{km}$ of a unique air pollution monitoring station, were aged $18-35$ years and had had at least 2 prenatal care visits during their pregnancy. Women were excluded from the study if they had a history of pregnancy complication such as gestational diabetes; pregnancyinduced hypertension; cardiovascular, renal or pulmonary disease; anaemia during pregnancy; a history of recurrent abortion, infertility or previous LBW baby; experience of severe stress during pregnancy; or being an active/passive smoker or drug abuser.

All women referred to the maternity hospitals and who complied with inclusion/exclusion criteria during the study period were entered into the study.

Monitoring data from Tehran Air Quality Control Company were used to estimate mean exposure rates during the whole pregnancy and for each trimester. The parameters of air pollutants were measured for each individual mother. Daily data were available for $\mathrm{PM}_{10} \mathrm{SO}_{2}$ exposure, while $\mathrm{NO}_{2}$ and $\mathrm{O}_{3}$ exposure were measured hourly and $\mathrm{CO}$ exposure was measured every 8 hours. To estimate exposure to each pollutant over the pregnancy period and each trimester, the residential address during pregnancy was considered. The distance between the participants' address and the closest monitoring data was determined using GIS programming. In cases where the addresses were assigned for more than 1 monitoring station, we used the data of the closest one.

After sampling, risk factors for low birth weight other than air pollution, such as maternal age, maternal education, maternal job, socioeconomic factor, stress status, number of prenatal care visits, weight gain during pregnan$c y$, gestational age, sex of the baby and planned pregnancy were analysed and it did not show any statistical significance between LBW and normal birth weight groups. The mean score of stress status was measured by Holmes and Rahe stress scale) $[17,18]$.

Logistic regression analysis was conducted to examine the predictive effect of air pollution on LBW. To do this analysis, birth weight was considered a dependent variable and was categorized into 2 groups: $<2500 \mathrm{~g}$ and $\geq 2500 \mathrm{~g}$. Other variables were entered into the model as key independent variables. Trimester exposures were modelled as categorical variables using inter-quartile ranges (IQRs). Odds ratios (ORs) of LBW with $95 \%$ confidence interval (CI) were calculated. This method has been applied in previous air pollution studies $[13,14]$.

\section{Analysis}

Analyses were done using chi-squared, $t$-test and logistic regression with SPSS software, version 15. $P<0.05$ was considered statistically significant.

\section{Results}

In total, 225 pregnant women were examined in this study. Mean age was 25.8 [standard deviation (SD) 4.6] years and mean duration of pregnancy 39 (SD 1.2) weeks. The mean birth weight of the babies was 3.12 (SD 0.49) kg. Only 35 women gave birth to LBW babies. Table 1 presents the demographic characteristics of the women who had babies with low and normal birth weight. There were no significant differences between the 2 groups in terms of demographic characteristic $(P \geq 0.05)$. 


\begin{tabular}{|c|c|c|c|}
\hline $\begin{array}{l}\text { Table } 1 \text { Demographic characteristics } \\
\text { babies and those who had babies w }\end{array}$ & $\begin{array}{l}\text { women who hac } \\
\text { ow birth weight }\end{array}$ & $\begin{array}{l}\text { normal weigh } \\
\text { (LBW) }\end{array}$ & NBW) \\
\hline Variable & NBW $(n=190)$ & $\operatorname{LBW}(n=35)$ & $P$-value \\
\hline & Mean (SD) & Mean (SD) & \\
\hline Maternal age ${ }^{\mathrm{a}}$ (years) & $26(4.5)$ & $24(4.8)$ & 0.10 \\
\hline Stress scoring ${ }^{\mathrm{a}}$ & $47(4.1)$ & $46(9.1)$ & 0.96 \\
\hline Number of prenatal care visits ${ }^{a}$ & $10.8(2.9)$ & $10.1(3.0)$ & 0.22 \\
\hline Weight gain during pregnancy $(\mathrm{kg})^{\mathrm{a}}$ & $12.7(5.7)$ & $11.8(4.2)$ & 0.35 \\
\hline Gestational age (weeks) ${ }^{\mathrm{a}}$ & $39.1(1.1)$ & $38.1(1.6)$ & 0.1 \\
\hline & $\%$ & $\%$ & \\
\hline Maternal education ${ }^{b}$ & & & 0.18 \\
\hline No education & 6 & 6 & \\
\hline Primary school & 34 & 18 & \\
\hline High school & 23 & 30 & \\
\hline Above high school & 37 & 46 & \\
\hline Maternaljob ${ }^{b}$ & & & 0.26 \\
\hline Working in the home & 97 & 95 & \\
\hline Employed outside the home & 3 & 5 & \\
\hline Birth order (first born) & 54 & 65 & 0.26 \\
\hline Infant sex ${ }^{b}$ (male) & 57 & 43 & 0.20 \\
\hline Planned pregnancy (yes) & 72 & 68 & 0.66 \\
\hline
\end{tabular}

${ }^{a}$ Student t-test.

${ }^{b} \chi^{2}$ test.

$S D=$ standard deviation

Table 2 shows mean exposure to pollutants and the inter-quartile range during the whole pregnancy as well as the crude OR for LBW. In order to determine the most vulnerable trimester of pregnancy, further assessment of exposure to pollutants during the different trimesters of pregnancy was made ( $\mathrm{Ta}$ ble 3). From the data in both tables, $\mathrm{CO}$ exposure was a significant risk factor for LBW during the whole pregnancy (OR $=2.08$, 95\% CI: $1.7-4.6, P=0.03)$ and in the second trimester $(\mathrm{OR}=3.96,95 \%$ reported in a previous study in Tehran [15]. The difference might be due to the sample size: our study was much smaller, 225 women versus 4734 women.

Several reports support the possibility of a negative effect of $\mathrm{CO}$ exposure on birth weight $[6,11,19,20]$. Our study indicated that exposure to ambient CO levels during pregnancy was associated with LBW. This finding of an inverse association between maternal $\mathrm{CO}$ exposure during pregnancy and LBW is consistent with some reports in previous studies [14,21]. Furthermore, the present study showed a significant association between maternal exposure during the second trimester of pregnancy and LBW. In contrast with this, some studies $[14,21]$ found that there was the association between exposure to pollutants during the third trimester and LBW, while another study reported such an association in the first trimester [8]. This inconsistency between different studies might be due to different times of year when the studies were carried out as pollution levels vary with season. However in this study we controlled for certain other risk factors which might influence birth weight.

No significant association was observed between other pollutants such as $\mathrm{PM}_{10} \mathrm{SO}_{2}, \mathrm{NO}_{2}$ and $\mathrm{O}_{3}$ and LBW. Although in a previous review study it was concluded that $\mathrm{PM}_{10}$ had an effect on LBW [22], we found no significant association in this regard. The postulated mechanism for the effect of $\mathrm{PM}_{10}$ is that $\mathrm{PM}_{10}$ may bind to placental growth factor resulted in decreased fetal-placental exchange of oxygen and nutrients, nutrient and oxygen supply during gestation are key factors regulating fetal growth rate [23]. If this is true, a probable justification for this contrasting result is that there would necessarily be a threshold effect [8], but in our study the level of exposure to $\mathrm{PM}_{10}$ may have been under the threshold level.

Additionally, the current study showed there was no significant association between exposure to $\mathrm{O}_{3}$ and 


\begin{tabular}{|c|c|c|c|}
\hline \multicolumn{4}{|c|}{$\begin{array}{l}\text { Table } 3 \text { Logistic regression analysis results for low birth weight }(<2500 \mathrm{~g}) \text { per inter- } \\
\text { quartile range increase in pollutants for each trimester }\end{array}$} \\
\hline Pollutant & $P$-value & OR & $95 \% \mathrm{Cl}$ \\
\hline \multicolumn{4}{|c|}{ First trimester } \\
\hline $\mathrm{CO}$ & 0.24 & 1.90 & $0.89-3.90$ \\
\hline $\mathrm{PM}_{10}$ & 0.34 & 0.63 & $0.40-1.14$ \\
\hline $\mathrm{SO}_{2}$ & 0.53 & 1.48 & $0.93-2.85$ \\
\hline $\mathrm{NO}_{2}$ & 0.62 & 1.19 & $0.63-1.92$ \\
\hline \multirow[t]{2}{*}{$\mathrm{O}_{3}$} & 0.14 & 1.85 & $0.83-3.70$ \\
\hline & \multicolumn{3}{|c|}{ Second trimester } \\
\hline $\mathrm{CO}$ & $0.02^{*}$ & 3.96 & $1.83-12.5$ \\
\hline $\mathrm{PM}_{10}$ & 0.90 & 0.63 & $0.52-1.84$ \\
\hline $\mathrm{SO}_{2}$ & 0.18 & 1.48 & $0.8-3.85$ \\
\hline $\mathrm{NO}_{2}$ & 0.20 & 1.92 & $0.83-3.92$ \\
\hline \multirow[t]{2}{*}{$\mathrm{O}_{3}$} & 0.28 & 1.45 & $0.33-1.43$ \\
\hline & \multicolumn{3}{|c|}{ Third trimester } \\
\hline $\mathrm{CO}$ & 0.85 & 1.09 & $0.43-2.88$ \\
\hline $\mathrm{PM}_{10}$ & 0.43 & 0.73 & $0.32-1.64$ \\
\hline $\mathrm{SO} 2$ & 0.14 & 0.54 & $0.23-1.24$ \\
\hline $\mathrm{NO}_{2}$ & 0.38 & 0.72 & $0.34-1.51$ \\
\hline $\mathrm{O}_{3}$ & 0.51 & 0.76 & $0.33-1.45$ \\
\hline
\end{tabular}

*Significant at $P<0.05$.

$O R=$ odds ratio; $C l=$ confidence interval.

LBW although a previous study found the association significant [11]. This inconsistency might be due to different average rates of exposure to $\mathrm{O}_{3}$ : in the previous study the mean exposure was $50 \mathrm{ppb}$ but in our study this was only $18.5 \mathrm{ppb}$.

No significant association was observed between $\mathrm{SO}_{2} / \mathrm{NO}_{2}$ and LBW, in line with the findings of earlier studies $[11,13]$.

This study had several strengths. First, this is one of the few studies excluding a number of confounding variables affecting LBW, therefore the effects of potential risk factors of LBW were controlled. Second, data collection in this study was done precisely through interviewing the women as well as looking for the participants' records to obtain more accurate data, while the previous studies used just birth data records that might be poorly completed [24]. Third, reliable measurements of criteria pollutant concentrations were obtained from several air monitoring stations in Tehran to achieve accurate exposure rates. Additionally, this is the only study that investigated all criteria of pollutants such as $\mathrm{CO}, \mathrm{PM}_{10} \mathrm{SO}_{2}, \mathrm{NO}_{2}$ and $\mathrm{O}_{3}$ Finally, in this study babies that were born in summer, the most polluted season, were included because seasonal variation in reproductive outcomes has been well documented [20].

However, this study had a limitation that could be the same of all such studies. The ambient air pollution measurements from stationary air pollution monitoring may not represent actual individual exposure. Measurement of individual exposure is not feasible [24].

Air pollution is one of the most important environmental and public health issues. Considering the impact of air pollution on birth weight, pregnant women, as an at risk group, should be trained and advised during pregnancy to limit their exposure to highly polluted areas of the city. Health workers should prepare accessible booklets regarding the effects of air pollution on health. Midwives could also play a key role in informing pregnant women about air pollution hazards and their effects on pregnancy outcome, like LBW.

In conclusion, we have demonstrated that exposure to current levels of CO pollution in Tehran throughout pregnancy, and especially in the second trimester, was strongly associated with LBW. Since LBW is the most important factor related to neonatal mortality and morbidity, our findings have critical public health implications. Nevertheless, further studies are needed to confirm fetal susceptibility to ambient air pollution since our study is one of only a few that have been carried out in the Middle East.

\section{Acknowledgements}

The authors wish to express their deepest appreciation to those women who participated in this study. The authors also thank the personnel of Tehran Air Quality Control Company for their kind assistance, especially Dr Rashidi and Mr Najafi for allowing the researchers to access the exposure data.

\section{References}

1. Bukowski R. Fetal growth in early pregnancy and risk of delivering infant. Prospective cohort study. BMJ Clinical Research, 2007, 334:836-838.

2. Taeusch $\mathrm{H}$ et al. Avery's diseases of the newborn, 2nd ed. Philadelphia, Saunders, 2004.
3. Behrman RE. Nelson's text book of pediatrics, 17th ed. Philadelphia, Saunders, 2004.

4. Sponge $\mathrm{C}$ et al. Progesterone for prevention of recurrent preterm birth: impact of gestational age at previous delivery. American Journal of Obstetrics \& Gynecology, 2005, 193(3):1127-1132. 
5. Lowdermilk D, Perry SH. Maternity and women's health, 8th ed. St. Louis, Missouri, Mosby, 2004.

6. Cunningham G et al. Williams obstetrics, 22nd ed. New York, McGraw-Hill, 2004.

7. Wang $\mathrm{X}$ et al. Association between air pollution and low birth weight. Environmental Health Perspectives, 1997, 105(5):514520.

8. Maisonet $\mathrm{M}$ et al. Relation between ambient air pollution and low birth weight. Environmental Health Perspectives, 2001, 109(3):48-52.

9. Bu Kowshi J. Association between air pollution and adverse pregnancy outcome in Vancouver. Environmental Health Perspectives, 2004, 112 (14):792-798.

10. Parker JD et al. Air pollution and birth weight among term infants in California. Pediatrics, 2006, 115(1):121-128.

11. Salam MT et al. Birth outcomes and prenatal exposure to ozone, carbon monoxide and particulate matter. Results from the children's health study. Environmental Health Perspectives, 2005, 113(11):1638-1644.

12. Rogers JF, Dunlop AL. Air pollution and very low birth weight infants: a target population? Pediatrics, 2006, 118(1):156-164.

13. Dugandzic $\mathrm{R}$ et al. The association between low level exposure to ambient air pollution and term low birth weight: a retrospective cohort study. Environmental health: a global access to social science, 2006, 5(2):3.

14. Bell M, Ebisu K, Belanger K. Ambient air pollution and low birth weight in Connecticut and Massachusetts. Environmental Health Perspectives, 2007, 115(7):1118-1124.

15. Vahdanian M, Tavafian S, Montazeri M. Correlates of low birth weight in term pregnancies: a retrospective study from Tehran. BMC Pregnancy and Childbirth, 2008, 8:12.
16. Motesaddi S. [Air pollution sustainable strategies, law and regulation]. Tehran, Markaze Motaleat va Barnamerizie Shahre, 2010 [in Farsi].

17. Tennant $\mathrm{C}$, Andrews G. A scale to measure the stress of life events. Australasian Psychiatry, 1976, 10(1):27-32.

18. Araban M. [Association between air pollution and low birth weight in women referring to Tehran Hospital 2008]. Tehran, Shaheed Beheshti University of Medical Sciences and Health Services, 2008 [In Farsi].

19. Leem $\mathrm{J}$ et al. Exposure to air pollution during pregnancy and preterm delivery. Environmental Health Perspectives, 2006, 114(6):905-910.

20. Jalaludin B et al. Impact of ambient air pollution on gestational age is modified by season in Sydney, Australia. Environmental Health, 2006, 6:16.

21. Brauer $\mathrm{M}$ et al. A cohort study of traffic-related air pollution impacts on birth outcomes. Environmental Health Perspectives, 2008, 116(5):680-686.

22. Sram $\mathrm{R}$ et al. Ambient air pollution and pregnancy outcomes: a review of the literature. Environmental Health Perspectives, 2005, 113(4):375-382.

23. Kanan $\mathrm{S}$ et al. Exposure to airborne particulate matter and adverse perinatal outcomes: a biologically plausible mechanistic frame work for exploring potential effect modification by nutrition. Environmental Health Perspectives, 2006, 114(11):1636-1642.

24. Sagive $\mathrm{SH}$ et al. A time series analysis of air pollution and preterm birth in Pennsylvania, 1997-2001. Environmental Health Perspectives, 2005, 113(5):602-606. 